\title{
An improved diagnostic assay for Lambert-Eaton myasthenic syndrome
}

\author{
Masakatsu Motomura, Irene Johnston, Bethan Lang, Angela Vincent, \\ John Newsom-Davis
}

\begin{abstract}
A new immunoprecipitation assay has been established for detecting antibodies to voltage-gated calcium channels (VGCCs) in Lambert-Eaton myasthenic syndrome (LEMS), using ${ }^{125 I-\omega-c o n o-~}$ toxin MVIIC, which binds to P-type VGCCs, to label extracts of human cerebellum. Fifty six of 66 serum samples (85\%) from patients with clinically and electrophysiologically definite LEMS were positive for the presence of VGCC antibodies, defined as a titre $>3$ SD above the mean for the healthy controls ( $n=$ 10). All disease controls $(n=40)$ were negative. This sensitive immunoassay should prove valuable in the diagnosis of LEMS.
\end{abstract}

(F Neurol Neurosurg Psychiatry 1995;58:85-87)

Keywords: Lambert-Eaton myasthenic syndrome; $\omega$ conotoxin; autoantibody; immunoassay; voltage-gated calcium channel

Lambert-Eaton myasthenic syndrome (LEMS) is an autoimmune disease, often associated with small cell lung cancer (SCLC), in which antibodies are directed against voltage-gated calcium channels (VGCCs) situated on the presynaptic nerve terminal. ${ }^{1}$ The VGCCs may be classified by their electrophysiological characteristics into at least four subtypes $(\mathrm{T}, \mathrm{L}, \mathrm{N}$, and $\mathrm{P}) .{ }^{23} \mathrm{We}$ have previously detected antibodies to $\mathrm{N}$-type VGCCs in a proportion of patients with LEMS using $\omega$-conotoxin GVIA ( $\omega$-CgTx), purified from the fish hunting cone snail (Conus geographus), which blocks neuronal Ntype VGCCs. ${ }^{4}$ Similar assays have been described by Sher and colleagues ${ }^{5}$ and Lennon and Lambert. ${ }^{6}$ In our series, however, less than $50 \%$ of serum samples were clearly positive and some autoimmune disease controls gave equivocal results. ${ }^{4}$ Recent evidence indicates that P-type VGCCs are present in some SCLC lines, ${ }^{7}$ are responsible for the control of neurotransmitter release at the mammalian neuromuscular junction, 8 and may be the targets for the autoantibodies. ${ }^{910}$ $\omega$-Conotoxin MVIIC ( $\omega-\mathrm{CmTx}$ ), synthesised from a sequence derived from a different cone snail (Conus magus), ${ }^{11}$ binds to P-type VGCCs in cerebellar extracts, and the binding sites were precipitated by three of four serum samples from patients with LEMS. ${ }^{12}$ We report here the results of a radioimmunoassay for 66 LEMS serum samples using ${ }^{125} \mathrm{I}-\omega$ CmTx to label extracted VGCCs.

\section{Methods and patients}

Synthetic $\omega$-conotoxin MVIIC was obtained from the Peptide Institute Inc (European Distributor, Scientific Marketing, UK). The toxin was iodinated with ${ }^{125} \mathrm{I}$ as previously described; ${ }^{13}$ the specific activity was $75-150$ $\mathrm{Ci} / \mathrm{mmol}$. Human cerebellum was obtained seven and 28 hours postmortem from two patients with ischaemic heart disease (aged 74 and 62 years respectively). It was frozen at $-70^{\circ} \mathrm{C}$ until required. The contralateral cerebellum was normal or showed age related changes only on routine histology. Safety precautions were taken throughout. The tissue was homogenised in $25 \mathrm{mM}$ Tris- $\mathrm{HCl} / 5 \mathrm{mM}$ HEPES buffer, $\mathrm{pH} 7 \cdot 4$, containing $0.32 \mathrm{M}$ sucrose, $1 \mu \mathrm{M}$ pepstatin, $2 \mu \mathrm{M}$ leupeptin, $0.1 \mathrm{mM}$ phenylmethysulphonylfluoride, and $20 \mu \mathrm{g} / \mathrm{ml}$ soybean trypsin inhibitor, and centrifuged. The membrane pellets were resuspended in the same buffer with $2 \%$ digitonin and rotated for an hour. The supernatant was separated by centrifugation at $13000 \mathrm{rpm}$ for 10 minutes. Cerebellum extract $(25 \mu \mathrm{l})$ containing about $30 \mathrm{fmol}$ of binding sites, was labelled with ${ }^{125} \mathrm{I}-\omega-\mathrm{CmTx}$ for two hours $(1.5 \mathrm{nM})$ and incubated overnight with serum $(1 \cdot 25-10 \mu \mathrm{l}$ diluted $1: 10)$ from patients with LEMS or controls. Excess goat antihuman IgG serum was then added to precipitate serum antibodies. Each sample was centrifuged and the pellets washed twice with $20 \mathrm{mM}$ phosphate buffer pH $7 \cdot 4$ containing $0 \cdot 1 \%$ Triton $\mathrm{X}-100$, before counting. All steps were performed at $4^{\circ} \mathrm{C}$. The specific binding was calculated from the total ${ }^{125} \mathrm{I}-\omega-\mathrm{CmTx}$ precipitated minus the non-specific binding determined by performing the assay in the presence of excess unlabelled $\omega$-CmTx (100 nM). Serum samples were available from 66 patients with typical clinical and EMG features of LEMS. The EMG criteria comprised (a) a reduced amplitude of the resting compound muscle action 
potential (CMAP) in abductor digiti minimi $(<8.5 \mathrm{mV})$ and $(b)$ an increment in CMAP amplitude after 15 seconds maximum voluntary contraction of the muscle $>100 \%$ of resting CMAP. ${ }^{14}$ Twenty two patients had histologically proved small cell lung carcinoma (SCLC), and 29 patients had been followed up for more than five years without signs of SCLC (no cancer detected, NCD). The SCLC status of the remaining 15 patients, followed up for less than five years, was regarded as uncertain (SU). The 50 controls were 10 healthy subjects, and 10 patients each with either SCLC without neurological symptoms, myasthenia gravis, other neurological diseases, or rheumatoid arthritis/systemic lupus erythematosus.

\section{Results}

The figure (A) shows quantitative precipitation of ${ }^{125} \mathrm{I}-\omega-\mathrm{CmT}$-VGCC from digitonin extracted cerebellum from two patients with LEMS. A healthy control serum showed nonspecific binding only. To determine antibody titres routinely, $10 \mu \mathrm{l}$ of serum was tested first and those samples precipitating $>10 \mathrm{fmol}$ of
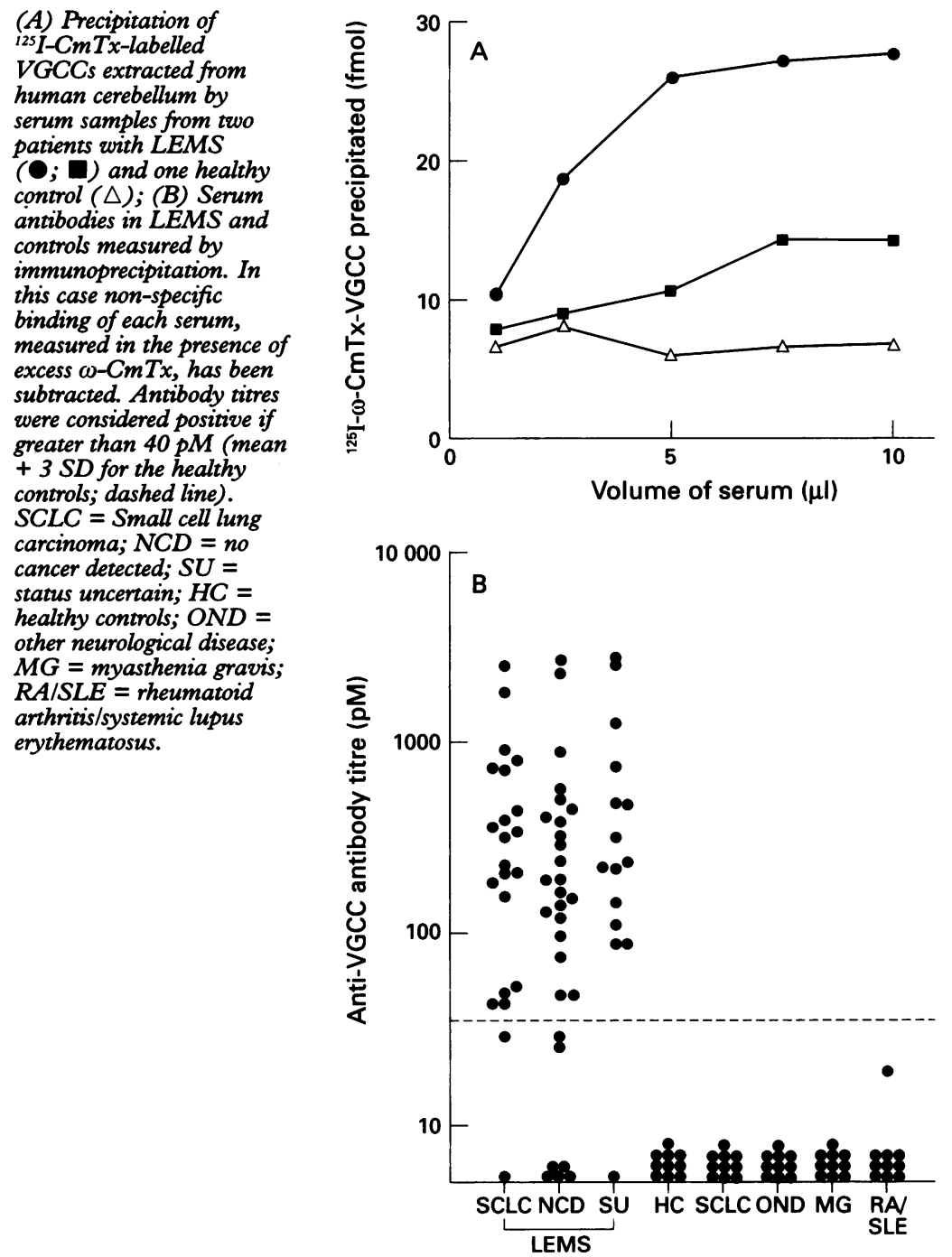

${ }^{125} \mathrm{I}-\omega-\mathrm{Cm} \mathrm{Tx}$ binding sites were retested using $2 \cdot 5 \mu \mathrm{l}$. Results are expressed as pmol specific ${ }^{125} \mathrm{I}-\omega-\mathrm{Cm} \mathrm{Tx}$ binding sites precipitated/litre of serum after subtraction of non-specific binding (see methods).

Fifty six of 66 LEMS samples (85\%) were positive for the presence of VGCC antibodies, defined as a titre $>40 \mathrm{pM}$ (3SD above the mean for the healthy controls; figure (B), dotted line). The mean titres in the three clinical groups (SCLC, NCD, SU) did not differ significantly. The proportions of patients positive for antibody in the three groups were $90 \%, 76 \%$, and $93 \%$ respectively. The antibody titres for all disease control samples $(n=$ $40)$ were negative $(<40 \mathrm{pM})$.

\section{Discussion}

In our previous study ${ }^{4}$ we showed that antibodies could be detected using ${ }^{125} \mathrm{I}-\omega-\mathrm{CgTx}$ to label N-type VGCCs, but this assay yielded positive titres in only $44 \%$ of patients with LEMS. The role of anti-N-type VGCC antibodies is uncertain, but they might contribute to the disturbance of the autonomic nervous system in LEMS as N-type VGCCs are concerned in transmitter release from some autonomic nerves. ${ }^{15}$

The use of P-type VGCCs should provide a better diagnostic assay because this channel subtype is responsible for neurotransmitter release at the mammalian neuromuscular junction. ${ }^{8}$ Also LEMS IgG blocked potassium stimulated $\mathrm{Ca}^{2+}$ flux in a human SCLC cell line, leading to the suggestion that P-type VGCCs might be the principal target for LEMS IgG. ${ }^{10}$ Moreover, similar lines have been shown to express mRNA for P-type VGCCs. ${ }^{7}$ In our present study we have detected positive titres in $85 \%$ of 66 patients with LEMS, using ${ }^{125} \mathrm{I}-\omega-\mathrm{CmTx}$. Although $\omega$ CgTx also binds to cerebellar extracts, less than $25 \%$ of the serum samples were positive when ${ }^{125} \mathrm{I}-\mathrm{CgTx}$ was substituted for ${ }^{125} \mathrm{I}-\mathrm{Cm} \mathrm{Tx}$ (unpublished data), further suggesting that the $\omega-\mathrm{CmTx}$-binding VGCCs are a more important antigenic target in LEMS. Human cerebellum extract was used as a source of the VGCCs; cerebellum from other species, human SCLC lines, or neuronal cell lines may provide an alternative source. This new assay should prove useful in the diagnosis and monitoring of disease progression.

We are grateful to Drs KR Mills and NMF Murray for electrophysiological studies, to Drs DA Isenberg, G Elrington, and DC Talbot for control serum, and to Dr B McDonald for ptaining the cerebellar samples. MM holds a Wellcome obtaining the cerebellar samples. MM holds a Wellcome Research Travelling Fellowship. This work was supported by the Medical Research Council and the Sir Jules Thorn
Charitable Trust.

1 Lambert EH, Elmqvist D. Quantal components of endplate potentials in the myasthenic syndrome. Ann NY Acad Sci 1971;183:183-99.

2 Tsien RW, Lipscombe D, Madison DV, Bley KR, Fox AP Multiple types of neuronal calcium channels and their
selective modulation. Trends Neurosci 1988;11:431-8.

3 Llinas R, Sugimori M, Lin J-W, Cherskey B. Blocking and isolation of a calcium channel from neurons in mammals and cephalopods utilizing a toxin fraction (FTX) from funnel-web spider poison. Proc Natl Acad Sci USA 1989;86:1689-93.

4 Leys K, Lang B, Johnston I, Newsom-Davis J. Calcium channel autoantibodies in the Lambert-Eaton myasthenic syndrome. Ann Neurol 1991;29:307-14. 
5 Sher E, Gotti C, Canal N, Scoppetta C, Piccolo G, Evoli A, Clementi F. Specificity of calcium channel autoantibodies in Lambert-Eaton myasthenic syndrome. Lancet 1989;ii: 640-3.

6 Lennon VA, Lambert EH. Autoantibodies bind solubilized calcium channel $\omega$-conotoxin complexes from small cel lung carcinoma: A diagnostic aid for Lambert-Eaton myasthenic syndrome. Mayo Clin Proc 1989;64: 1498-504.

7 Oguro-Okano M, Griesmann GE, Wieben ED, Slaymaker SJ, Snutch TP, Lennon VA. Molecular diversity of neuronal-type calcium channels identified in small cell neuronal-type calcium channels identified in smal

8 Uchitel OD, Protti DA, Sanchez V, Cherskey BD, Sugumori M, Llinas R. P-type votage-dependent calcium channel mediates presynaptic calcium influx and transmitter release in mammalian synapses. Proc Nat Acad Sci USA 1992;89:3330-3.

9 Johnston I, Lang B, Leys K, Newsom-Davis J. Heterogeneity of calcium channel autoantibodies detected using a small-cell lung cancer line derived from a Lambert-Eaton myasthenic syndrome patient. Neurology 1994;44:334-8.
10 Lang B, Johnston I, Leys $\mathrm{K}$, et al. Autoantibody specificities in Lambert-Eaton myasthenic syndrome. Ann NY Acad Sci 1993;681:382-93.

11 Hillyard DR, Monje VD, Mintz IM, et al. A new peptide ligand for mammalian presynaptic $\mathrm{Ca}^{2+}$ channels. Neuron 1992;9:69-77.

12 Lennon VA, Krvzer T, Griesmann GE, et al. P-Like $\mathrm{Ca}^{2+}$ channels in human cerebellum and small cell lung carcinoma bind $\omega$-conotoxin-MVIIC and are immunoprecipitable by Lambert-Eaton myasthenic syndrome IgG that react highly with $\mathrm{N}$-type $\mathrm{Ca}^{2+}$ channels. Society for Neurosciences (abstract) 1993;19:1753.

13 Vincent A, Newsom-Davis J. Acetylcholine receptor antibody as a diagnostic test for myasthenia gravis: results in body as a diagnostic test for myasthenia gravis: results in 153 validated cases and 2967 diagnostic

14 Newsom-Davis J, Murray NMF. Plasma exchange and immunosuppressive drug treatment in the LambertEaton myasthenic syndrome. Neurology 1984;34:480-5.

15 De Luca A, Li CG, Rand MJ, Reid J, Thaina P, WongDusting HK. Effects of $\omega$-conotoxin GVIA on autonomic neuroeffector transmission in various tissues. $B r f$ Pharmacol 1990;101:437-47.

\section{Hughlings Jackson and the Holmes-Adie tonic pupil}

The names of Gordon Holmes ${ }^{1}$ and W James Adie ${ }^{23}$ are traditionally attached to the syndrome of myotonic pupils and tendon areflexia. Some 50 years earlier in 1881, mydriasis with pupillary paralysis was described clearly by Hughlings Jackson. ${ }^{4}$ In 1914 Oloff found negative Wasserman reactions in blood and CSF in an 18 year old boy with tonic pupils, thereby showing that syphilis-previously implicated-was not the cause. Harriman and Garland ${ }^{5}$ credited earlier papers dating to 1902 (Strassburger, Saener) that described tonic pupils.

Hughlings Jackson:

"A woman aged 26 was sent to see me simply because the right pupil was much larger than the left. It had been so three years . . . the right pupil was dilated and absolutely motionless to light, and also during accommodation, yet the accommodation itself on this side was perfect; this was severely tested by $\mathrm{Mr}$ Couper . . . this case at first puzzled me ... It occurred to me to test the knees. Neither I nor $\mathrm{Mr}$ Couper found the smallest trace of the knee phenomenon. Several times did I pertinaciously inquire for other symptoms of tabes; there were no other symptoms of any kind . . . Dr Buzzard ... confirmed the above observations."

Sir Gordon Holmes ${ }^{1}$ :

"Frequently no change in the size of the pupil was visible immediately on convergence, but when this was maintained for a few seconds the pupil slowly and gradually grew smaller, till its diameter equalled or was even narrower than that of the normal eye. The rate of contraction varied very much ... When contracted the pupil remains constant and when convergence is relaxed it dilates slowly."
Adie $^{3}$ described 19 patients, 13 with absent tendon reflexes, and noted 44 reported cases of tonic pupil. In an exemplary clinical essay, he outlined four incomplete forms (the last would not now be accepted).

"1. The complete form-typical tonic pupil and absence of reflexes.

2. Incomplete forms: a) tonic pupil alone; b) atypical phase of the tonic pupil alone (iridoplegia"; internal opthalmoplegia"); c) atypical phases of the tonic pupil with absent reflexes; d) absent reflexes alone." Adie did not claim originality, recognising descriptions from 1902. Holmes's work is not acknowledged in Adie's Brain paper. Adie commented on the past misconstrued attribution to syphilis: "A perversion of nervous activity" of the vegetative nervous system was, he thought, the cause.

It was the London ophthalmologist, James Ware (1756-1815), however, who furnished one of the earliest depictions in $1813 .{ }^{\circ}$

J M S PEARCE

1 Homes G. Partial iridoplegia associated with symptoms of ther diseases of the nervous system. Transactions of the Ophthalmological Society of the UK 1931;51:209-28.

2 Adie WJ. Complete and incomplete forms of the benign disorder characterised by tonic pupils and absent tendon reflexes. Br $₹$ Ophthalmol 1932;16:449-61.

3 Adie WJ. Tonic pupils and absent tendon reflexes: benign disorder sui generis; its complete and incomplete forms. Brain 1932;55:98-113.

4 Jackson JH. Paralytic affections. 1. On eye symptoms in locomotor ataxy. Transactions of the Ophthalmological Society of the UK 1881;1:139-54.

5 Harriman DGF, Garland H. The pathology of Adie's syndrome. Brain 1968;91:401-18.

6 Ware J. Philos Trans $R$ Soc Lond 1813;31-50 [see Dunn's biography of Ware. Br $\mathcal{F}$ Ophthalmol 1917;1:401-10] cited by Leake CD. In: Haymaker W, Schiller F, eds. Founders of Neurology. 2nd ed. Springfield, Ilinois: Founders of Neurolog. 